Private financing of higher education is clearly crucial to maintaining an efficient, quality-driven system, but it is not a panacea for the problems currently facing developing countries. The push for a more balanced mix of public and private funding is necessary, but the way it has been so whole-heartedly and rapidly embraced is disconcerting without further research on the economic consequences that cost sharing will have on developing countries in the long run.

\section{The New Landscape of International Student Mobility}

\section{Hey-Kyung Кон Chin}

Hey-Kyung Koh Chin is senior program officer of research and evaluation, at the Institute of International Education in New York City. She is also the editor of the Open Doors Report on International Educational Exchange. Address: Institute of International Education, 809 United Nations Plaza, New York, New York 10036. E-mail: HKOH@iie.org.

S ome patterns and shifts emerge in comparing data for

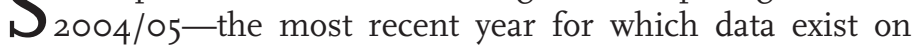
international students in US higher education from the Open Doors Report on International Educational Exchange-with the previous year. The regions of origin of international students remained virtually unchanged in 2004/05. As has been the case for many decades, the largest proportion of international students came from Asia (57 percent), up I percent from 2003/04. Enrollments from Europe (I3 percent) and Latin America (I2 percent) remained the same, while enrollments from Africa ( 6 percent) declined I percent, and those from North America (5 percent) and the Middle East ( 6 percent) remained unchanged. India was the leading place of origin of international students for the fourth year in a row, with 80,466 students in the United States (I4 percent of the total). But after several years of double-digit growth, the increase from $2003 / 04$ to $2004 / 05$ was only I percent. Five-year enrollment trends for the other three leading sending countries showed varied rates of growth: enrollments from China, the secondlargest sender, increased until 2002/03, declined in 2003/04, then increased slightly in 2004/05; enrollments from Japan increased until 2001/02, declined slightly in 2002/03, declined steeply in 2003/04, and increased again 2004/05; and enrollments from Korea experienced a steady increase throughout.

In the United States the distribution of international students by state has not changed much over time. The five leading host states in 2004/05 were California, New York, Texas, Massachusetts, and Florida. New York City was once again the largest metropolitan area hosting international students, followed by Los Angeles, Boston, Washington DC, and Chicago. International students tended to be heavily concentrated within the United States: the leading 25 host institutions were all doctoral research institutions, each of which hosted 3,000 or more international students and are located in just $\mathrm{I} 3$ of the 50 US states.

With respect to their personal profile, international students were largely studying business and management, followed by engineering. One major troubling shift in $2004 / 05$ was a 25 percent decline in international student enrollments in mathematics and computer sciences. Other fields of study that showed the largest declines in enrollments included social sciences (I5 percent) and fine and applied arts (I2 percent), with the largest growth in physical and life sciences (II percent) and intensive English language (8 percent). As in the past, the primary source of funding was personal and family funds, with almost two-thirds of international students (62 percent) relying on these funds to support their studies in the United States in 2004/05. The gender ratio has become steadily more balanced since the earlier years of the census, with 44 percent female students in 2004/05 versus 30 percent in the I970s. Unchanged over time are the marital status and visa status of international students, with 85 percent single and 87 percent coming to study on F (student) Visas in 2004/05.

The most significant change has been in total enrollments,

The gender ratio has become steadily more balanced since the earlier years of the census, with 44 percent female students in 2004/05 versus 30 percent in the 1970s.

which has generated a large degree of concern and discussion among US educators, government officials, and business leaders. In I954/55, there were 34,232 international students studying at US colleges and universities. Half a century later, in 2004/05, the number had grown to 565,039. This number represented a decline of I.3 percent from $2003 / 04$, which followed a 2.4 percent decline the previous year, and minimal growth of 0.6 percent in the year prior. These years followed on the heels of two consecutive years of 6.4 percent increases and nearly 30 years of fairly steady and sometimes strong growth. Given the recent reversal, what has been the impetus behind the declines?

\section{Reasons for the Decline}

Much of the decline has been attributed to tightened student visa review procedures implemented after September II, 200I, which included personal interviews for all applicants and other new screening measures. The addition of several hundred consular officers this past year to handle the backlog generated in spring and summer 2002 and 2003 by these new require- 
ments and a priority given to timely issuance of student visas reduced the waiting time and increased the visa approval rate to pre-September in levels in most countries. However, student perceptions have not caught up with reality. International students who might not have seriously considered studying abroad anywhere other than the United States became increasingly open to other options, especially those countries with quicker visa-issuing procedures.

For financial and geopolitical reasons, as well as the need for a highly educated labor force, the global competition for international students has been intensifying. Although competition has been eroding the US share in comparison with four of the leading host countries (Australia, France, Germany, and the United Kingdom) from 47 percent in $1997 / 98$ to 40 percent in 2003/04, the United States continued to host more than twice the number of its closest competitor, the United Kingdom, in 2004/05.

Many of the other leading host countries have developed international student recruitment strategies at the national level, supported by substantial financial investments. In contrast, because international education policy in the United States, like other elements of higher education policy, is highly decentralized, the federal government only plays a limited role. Instead, international recruitment plans are developed and carried out by individual institutions, with scarce resources for recruitment activities (at most institutions), and usually in competition with one another. There are other significant reasons for declining enrollments beyond student concerns over visa approval delays. The rising cost of US tuition, along with alternative access to US degrees-through distance education, branch campuses, and joint degrees-have also contributed to slower growth and, from some countries, declining numbers.

Not all of the declines can be attributed to post-September II perceptions about visa difficulties, to increased competition, or to domestic US conditions. Expanded capacity of both public and private tertiary education institutions at both the undergraduate and graduate levels has created more educational opportunities for students in their respective home countries. A number of these "sending countries" have also themselves become regional host countries as their higher education sector expands and their economies become globalized. The Institute of International Education's Atlas of Student Mobility, a web-based information resource, provides a snapshot of these dynamic paths of global international student mobility.

\section{Hints of a Possible Turnaround}

To supplement the Open Doors fall 2004 data by collecting responses from US institutions about the current semester, the Institute of International Education recently conducted a fall 2005 online survey in cooperation with leading professional organizations in the field of international education. While not as comprehensive as the data in Open Doors, the online survey does suggest some strengthening of international enrollments going forward. Of the 970 responding institutions overall, regardless of type of institution, 34 percent reported an increase, 33 percent reported a decline, and 34 percent reported level enrollments. Of the ro 6 responding institutions that enroll more than I,000 international students, 33 percent reported an increase, 43 percent reported a decline, and 24 percent reported level enrollments. Focusing on new enrollments (students beginning their studies in fall 2005), 40 percent reported an increase, 26 percent reported a decline, and 34 percent reported level enrollments. Of the responding institutions (Io6) that enroll more than I,000 international students, 5I percent reported an increase in new enrollments, 26 percent reported a decline, and 24 percent reported level enrollments.

The majority of respondents reported even levels of increase and decrease with regard to new student enrollments for coun-

\section{Because international education policy in the} United States, like other elements of higher education policy, is highly decentralized, the federal government only plays a limited role

tries overall. But in response to a breakdown by leading sending countries, more respondents reported increases rather than declines: 29 percent reported an increase $(20$ percent a decline) for new enrollments from China, and 36 percent reported an increase (I7 percent a decline) for Korea. Conversely, most respondents reported declining enrollments from large Muslim countries: 20 percent reported a decline in new enrollments from Indonesia (I3 percent an increase), I8 percent reported an increase (Io percent a decline) for Malaysia, and 20 percent reported an increase (I4 percent a decline) for Pakistan. Regarding new and continuing enrollments by academic level, Iog of the responding institutions (47 percent) noted that declines were more evident at the undergraduate level, 66 (29 percent) noted more declines at the graduate level, and 56 (24 percent) noted similar levels of declines at both levels.

In a separate survey conducted by the Council of Graduate Schools, the "2005 International Graduate Student Admissions Survey II: Final Applications and Admission," graduate institutions reported a 3 percent increase overall in new graduate international student enrollments over the previous year, 25 percent of responding institutions reported an increase in new enrollments from India and 29 percent reported an increase from China. New data from the Open Doors 2005/06 census will not be available until November 2006, but it appears likely, based on these smaller samples, that enrollment totals for many leading sending countries will have rebounded to pre-September in levels.

While these data offer some encouragement, the US government and US higher education institutions are still actively engaged in dialogue about how to reverse negative perceptions 
and how to streamline the review process for student visa applicants so that the United States remains the leading host country for international students. A summit of university presidents hosted by the US secretary of state and US secretary of education, held in January 2005, articulated a strong commitment at the national level, while US higher education institutions continue to develop their own strategies to attract international students.

For the Open Doors 2005 Report on International Educational Exchange or the fall 2005 online survey, see: http://opendoors.iienetwork.org. For the Atlas of Student Mobility project, see: http://atlas.iienetwork.org.

\section{Where Are the International Students Going?}

\section{Geographic Locus}

Most recent reports note shifts in the country of origin of foreign students. Clearly the numbers from Muslim countries are down; from 2002 there was a sharp drop in students from the Middle East, and this past year, the numbers from Indonesia fell off. Lately there is also an apparent decline in students from China.

Surprisingly, in view of the economic trade rhetoric associated with recent reports of foreign student enrollments, there is little commentary on the geographic areas foreign students are inclined to select and reject. But a look at the numbers suggests a shift away from the Northeast toward the Southwest and mountain states. Within each region, there are more complicated patterns. For example, while the Northeast is down, Maryland is steadily up. And while the West is down, Hawaii is up.

\section{Sectoral Shifts}

Another perspective on recent trends is to consider the sectoral choices of foreign students. Using I994 as the base year, most sectors experienced substantial growth in foreign student enrollments through 200I with the exception of the baccalaureate sector that first experienced a sharp drop through 2000 , followed by a slow recovery. For most of the other sectors, 200I was the beginning of a downturn with signs of recovery in 2004. In contrast, for the university sector (including Research I and II and Doctoral I and II), 2004 was the first instance of a substantial downturn in over two decades.

The downturn for the university sector is especially notable as a relatively large proportion of the foreign students in this sector receive graduate assistant and research assistant stipends. Thus, despite the substantial incentives offered by this sector, there has been a decrease in the number of foreign students attracted to the United States to pursue these opportunities. Indeed, the numbers are down even though, according to the Council of Graduate Schools, many graduate schools report they have increased their admissions rates in an attempt to maintain their traditional intake of foreign-born graduate students.

Despite the substantial incentives offered by this
sector, there has been a decrease in the number of
foreign students attracted to the United States to
pursue these opportunities.

Turning to the other sectors, it can be argued that their primary focus is on providing associate-level or undergraduate education for a fee. To learn more about the behavior of the institutions in these sectors, we sampled ro7 institutions in the liberal arts sector, 70 in the specialized sector, and 40 in the associate sector and compiled detailed statistical profiles of each institution from I994 through 2004. The following generalizations are based on our analysis of the respective samples. 